\title{
The role of serum response factor in hepatocellular carcinoma: An association with matrix metalloproteinase
}

\author{
KYUNG RYOUL KIM*, JUN SANG BAE* , HA NA CHOI, HO SUNG PARK, \\ KYU YUN JANG, MYOUNG JA CHUNG and WOO SUNG MOON
}

\begin{abstract}
Department of Pathology, Chonbuk National University, Medical School, Research Institute of Clinical Medicine, and Research Institute for Endocrine Sciences, Jeonju 561-756, Republic of Korea
\end{abstract}

Received June 22, 2011; Accepted July 25, 2011

DOI: 10.3892/or.2011.1421

\begin{abstract}
Serum response factor (SRF) regulates transcription of immediate early genes and triggers proliferation, migration and differentiation in several types of cells. Matrix metalloproteinases (MMPs), a group of zinc-dependent endopeptidases, play a crucial role in tumor invasion and metastasis. However, expression of SRF and its association with MMPs in hepatocellular carcinoma (HCC) have not been elucidated. We examined the expression levels of SRF, MMP-2 and MMP-9 in HCC tissues using Western blot assay. We also examined the effect of SRF on MMP expression and enzyme activity in HCC by transfection of SRF cDNA in HLE cells. Protein expression of SRF, MMP-2 and MMP-9 showed a significant increase in HCC tissues, compared with those of corresponding non-tumor tissues. High SRF expressing HCC tissues showed higher levels of expression of MMP-2 and MMP-9, compared with low SRF expressing HCC tissues. In addition, overexpression of SRF in HLE cells led to increased levels of expression of mRNA and protein, as well as increased enzyme activity of MMP-2 and MMP-9. Overexpression of SRF also led to significantly enhanced migration of HLE cells. These results suggest that overexpression of SRF in HCC may play an important role in tumor cell migration and invasion through upregulation of MMP-2 and MMP-9.
\end{abstract}

\section{Introduction}

Hepatocellular carcinoma (HCC) is the sixth most common solid malignant tumor worldwide, with an incidence of

Correspondence to: Professor Woo Sung Moon, Department of Pathology, Chonbuk National University, Medical School, Jeonju, Republic of Korea

E-mail: mws@chonbuk.ac.kr

\section{*Contributed equally}

Key words: carcinoma, hepatocellular, serum response factor, matrix metalloproteinases
626,000 cases and 598,000 deaths annually, making it the third most common cause of cancer deaths throughout the world $(1,2)$. In recent years, considerable advances have been made in diagnosis and treatment of HCC. However, HCC is still associated with a high rate of mortality, and the prognosis of this tumor is poor, even with treatment that is considered potentially curative. Morbidity and mortality of patients with $\mathrm{HCC}$ is predominantly the result of tumor invasion and metastasis (3).

Serum response factor (SRF) is a transcription factor of the MADS box family, which is composed of 508 amino acids containing three major domains: a serum response element (SRE) DNA binding domain, a transactivation domain, and several phosphorylation sites (4-8). Serum response factor (SRF) is a transcription factor involved in regulation of many genes, including immediate early genes, such as $c$-Fos, $J u n$, and $E g r$, and tissue-specific genes involved in cellular activities, such as proliferation, migration, differentiation, angiogenesis, and apoptosis (4-11). Recent studies have strongly implicated a role for SRF in tumor progression, including HCC $(12,13)$.

Matrix metalloproteinases (MMPs) are a family of structurally related zinc-dependent endopeptidases, which are collectively capable of degrading essentially all components of extracellular matrix (ECM), including collagens, elastins, gelatin, matrix glycoproteins, and proteoglycan $(14,15)$. They play an important role in various physiological processes, including tissue remodeling, organ development, angiogenesis, inflammatory processes, vascular and autoimmune disorders, and in cancer (14-17). Among the MMPs, activity of MMP-2 and -9 has been associated with progression of HCC and some studies have demonstrated an association of overexpression of MMP-2 or -9 with invasion and metastasis of $\operatorname{HCC}(18,19)$. However, SRF expression and its association with MMPs in HCC have not been elucidated. We examined the expression and role of SRF in HCC, specifically in association with MMPs expression.

In the present study, we examined a) expression levels of SRF, MMP-2, and -9 in HCC tissues, b) the relationship between expression of SRF and MMP-2, -9 in HCC tissues, c) the effect of SRF in expression and enzyme activities of MMP-2 and -9 using SRF-overexpressed HCC cells, and d) the role of SRF in migration of HCC cells. 


\section{Materials and methods}

Cell culture. The human HCC cell line, HLE, was purchased from the Health Science Research Resources Bank (Osaka, Japan). HLE cells were maintained in Dulbecco's modified Eagle's medium (DMEM) supplemented with penicillin and streptomycin $(100 \mathrm{U} / \mathrm{ml})$ and $10 \%$ fetal bovine serum (Gibco BRL, Gaithersburg, MD, USA), and the cells were grown at $37^{\circ} \mathrm{C}$ in a humidified $5 \% \mathrm{CO}_{2}$ incubator.

Stable transfection of SRF complementary DNA. A previously described method was used in performance of stable transfection (13). Briefly, cells were rinsed with serum-free medium and without antibiotics, and were transfected with pcDNA 3.1-SRF $1 \mu \mathrm{g} /$ lipofectin 8-10 $\mu \mathrm{l}$ or pcDNA3.1 $1 \mu \mathrm{g} /$ lipofectin $8-10 \mu \mathrm{l}$ (mock control), followed by incubation at $37^{\circ} \mathrm{C}$ in a $5 \% \mathrm{CO}_{2}$ incubator for $12 \mathrm{~h}$. The medium was then replaced by DMEM with $10 \%$ FBS and without antibiotics. After $18 \mathrm{~h}$, cells in each group were removed for detection of transient expression of SRF by Western blot methods, whereas others were continuously cultured for stable expression of SRF. Cells were subcultured with DMEM with 10\% FBS with G418 $(600-800 \mu \mathrm{g} / \mathrm{ml})$. After 2 weeks of culture in the presence of G418, positive clones were selected and transferred into 24-well plates.

RNA extraction and RT-PCR analysis. Total RNA was extracted using TRI Reagent (Molecular research center, Inc., Cincinnati, $\mathrm{OH}$ ) according to the manufacturer's protocol. The concentration of total RNA can be determined by spectrophotometry. Reverse transcription was carried out using reverse transcriptase (Roche Applied Science, Mannheim, Germany), which involved preparation of a master-mixture. The mastermixture was comprised of $5 \mathrm{X}$ colorless Go Taq Flexi buffer, $25 \mathrm{mM} \mathrm{MgCl}{ }_{2}, 10 \mathrm{mM}$ dNTPs, and Go Taq polymerase (Promega, Madison, WI), each of both forward and reverse primers and extracted RNA in a $25 \mu 1$ reaction mixture. Conditions for PCR of MMP- 2 were: $95^{\circ} \mathrm{C}$ for $2 \mathrm{~min}, 58^{\circ} \mathrm{C}$ for $50 \mathrm{sec}, 72^{\circ} \mathrm{C}$ for $30 \mathrm{sec}$, and a final extension at $72^{\circ} \mathrm{C}$ for $5 \mathrm{~min}$ for 35 cycles; and MMP-9 conditions were: $95^{\circ} \mathrm{C}$ for $2 \mathrm{~min}$, $62^{\circ} \mathrm{C}$ for $30 \mathrm{sec}, 72^{\circ} \mathrm{C}$ for $30 \mathrm{sec}$, and a final extension at $72^{\circ} \mathrm{C}$ for 5 min for 35 cycles. In this study, primers used were: MMP-2: 5'-CGGCCGCAGTGACGGAA-3' and 5'-AAGAA CTTCCGTCTGTCCCAGGATG-3'; MMP-9: 5'-GACGCA GACATCGTCATCCAGTTT-3' and 5'-TTTGGAAACGCAG ATGGCGCGGC-3'; $\beta$-actin: 5'-CGCGAGAAGATGACCCA GATC-3' and 5'-TCGTGATGGACTCCGGTGA-3'.

Protein extraction and Western blot analysis. HCC tissues and cells were homogenized and extracted with PRO-PREP Protein Extraction Solution (iNtRON Biotechnology Inc., Korea). Lysates were incubated on ice for $10 \mathrm{~min}$, and centrifuged at $14,000 \mathrm{rpm}$ for $10 \mathrm{~min}$ at $4^{\circ} \mathrm{C}$. Protein concentration was determined according to the Bradford method (Bio-Rad, Richmond, CA). Proteins were separated by electrophoresis on an $8 \%$ SDS-polyacrylamide gel, and the separated proteins were electrotransferred to a polyvinylidene difluoride (PVDF) membrane using a semidry transfer method (Bio-Rad). The membrane was then blocked with $5 \%$ nonfat dry milk in Tris-buffered saline (TBS)-0.1\% Tween-20 (15 mM NaCl,
$100 \mathrm{mM}$ Tris- $\mathrm{HCl}, \mathrm{pH} 7.5)$ for $1 \mathrm{~h}$ to reduce nonspecific binding. The membrane was incubated with anti-SRF (Santa Cruz Biotechnology, Santa Cruz, CA), anti-MMP-2 (R\&D Systems, Minneapolis, MN), and anti-MMP-9 (Thermo Fisher Scientific, Scotts Valley, CA) overnight at $4^{\circ} \mathrm{C}$. The membrane was incubated for $1 \mathrm{~h}$ at room temperature with corresponding secondary antibodies, and the immune complexes were visualized using the ECL detection system (Amersham Biosciences, Buckinghamshire, UK) and exposed to a luminescent image analyzer (LAS-3000, Fuji Film, Tokyo, Japan). Equal loading of proteins in each lane was confirmed by probing the membrane with mouse anti- $\beta$-actin (Sigma, St. Louis, MO) or rabbit anti-GAPDH (Sigma).

Measurement of MMP-2 and -9 enzyme activity. Assessment of MMP-2 and -9 activities of conditioned media was performed using the colorimetric Biotrak MMP-2, -9 activity assay (GE Healthcare Biosciences, Piscataway, NJ), according to the manufacturer's instructions. The assay uses the pro-form of a detection enzyme that can be activated by captured active MMPs into an active detection enzyme, through a single proteolytic event. Standard and samples were incubated in microplate wells pre-coated with anti-MMP-2 or anti-MMP-9 antibody. Optical densities were quantified using a microtiter plate reader (Bio$\mathrm{Rad}$ ) at a wavelength of $405 \mathrm{~nm}$, referenced to $650 \mathrm{~nm}$. Three samples were used for each experimental condition. Experiments were performed in triplicate and mean values were calculated.

Wound-healing assay. HLE cells transfected with either the SRF expression plasmid or the control vector plasmid were cultured in $0.2 \%$ gelatin-coated 6 -well plates containing DMEM medium until confluence. Confluent cells were scraped with a sterile pipette tip and washed with serum-free DMEM medium to remove cellular debris. Cells were then starved in serum-free DMEM medium for $12 \mathrm{~h}$. After $12 \mathrm{~h}$, cells were treated with $10 \%$ fetal bovine serum for $24 \mathrm{~h}$. Migration of cells into the wound area was allowed at $37^{\circ} \mathrm{C}$ in a $5 \% \mathrm{CO}_{2}$ incubator for $24 \mathrm{~h}$. The wound area was photographed with a Nikon digital camera connected to the microscope at $0,6,12$, and $24 \mathrm{~h}$. All experiments were performed in triplicate.

Statistical analysis. Data are expressed as means $\pm \mathrm{SD}$ for three or more independent experiments. Difference of expression of SRF, MMP-2, and -9 between HCC and non-malignant hepatocytes was tested by the Student's t-tests. $\mathrm{P}<0.05$ were considered to indicate statistical significance.

\section{Results}

Expression of SRF, MMP-2, and -9 in hepatocellular carcinoma tissues. We evaluated expression of SRF, MMP-2, and -9 in 16 cases of HCC tissues and corresponding non-tumor hepatic tissue. Representative SRF, MMP-2, -9 expressions are shown in Fig. 1A. In HCC samples, SRF, MMP-2 and -9, were significantly increased by 2-, 1.5-, and 2.5-fold, respectively, when compared with those of the corresponding non-tumor tissues (Fig. 1A).

Relationship between SRF expression and expression of $M M P-2$ and -9 in hepatocellular carcinoma tissues. Image J software was used for measurement of SRF protein band 
A

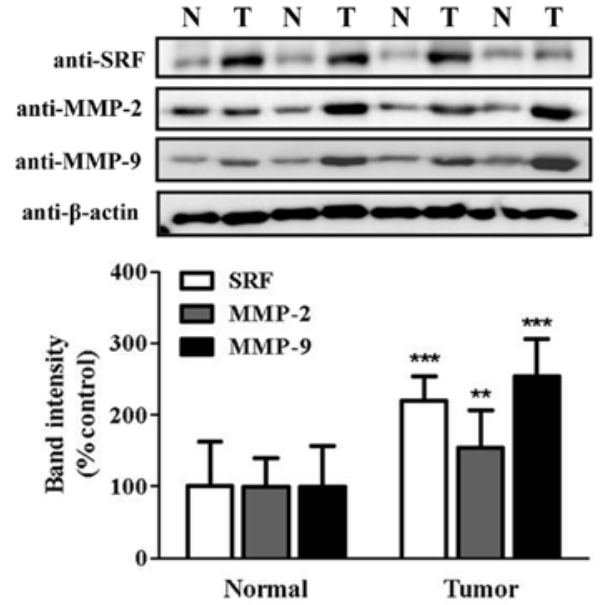

B

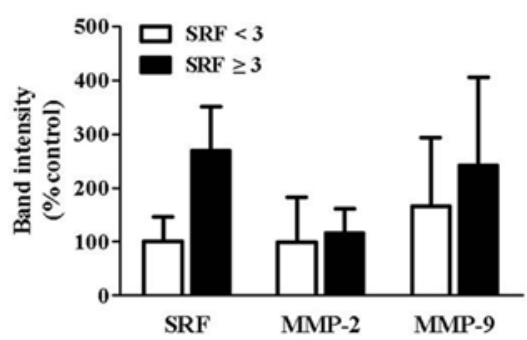

Figure 1. Protein levels of SRF, MMP-2, and -9 in hepatocellular carcinoma (HCC) tissues. (A) Expression levels of SRF, MMP-2, and -9 in HCC tissues was significantly up-regulated when compared with those of corresponding non-tumor tissues $\left({ }^{* *} \mathrm{P}<0.01 ;{ }^{* * * *} \mathrm{P}<0.001\right)$. (B) The high SRF expression group (SRF intensity $\geq 3$-fold as compared to that of non-tumor tissues) showed increased expression of MMP-2 and -9 when compared with those of the low SRF expression group ( $\mathrm{SRF}<3$-fold as compared to that of non-tumor tissues).

intensities. Then, by adoption of cut-off values according to SRF band intensities 3-fold level, compared with that of nontumor tissues, we divided results according to the high SRF expression group (SRF intensity $\geq 3$-fold) and the low SRF expression group ( $\mathrm{SRF}<3$-fold). According to the results, the high SRF expression group (7 cases) showed higher expression of MMP-2 and -9 than the low SRF expression group (9 cases) (Fig. 1B).

Overexpression of SRF in HLE cells induced MMP-2 and -9 gene expression. Based on the above results, we attempted to determine whether SRF increases MMPs production in SRF-transfected HLE cells. Using RT-PCR, we first analyzed mRNA levels of MMP-2 and -9 in SRF-transfected HLE cells. According to the results, expression of MMP-2, -9 mRNA showed a marked increase in SRF-transfected HLE cells, when compared with normal control cells (Fig. 2). Next, we analyzed the protein levels of MMP-2, -9 in SRF-transfected HLE cells by Western blotting. Overexpression of SRF in HLE cells resulted in markedly increased expression of MMP-2 and -9 (including pro-, latent-, active form), when compared with those of the control. Representative SRF, MMP-2, and -9 protein expressions are shown in Fig. 3. In SRF-transfected

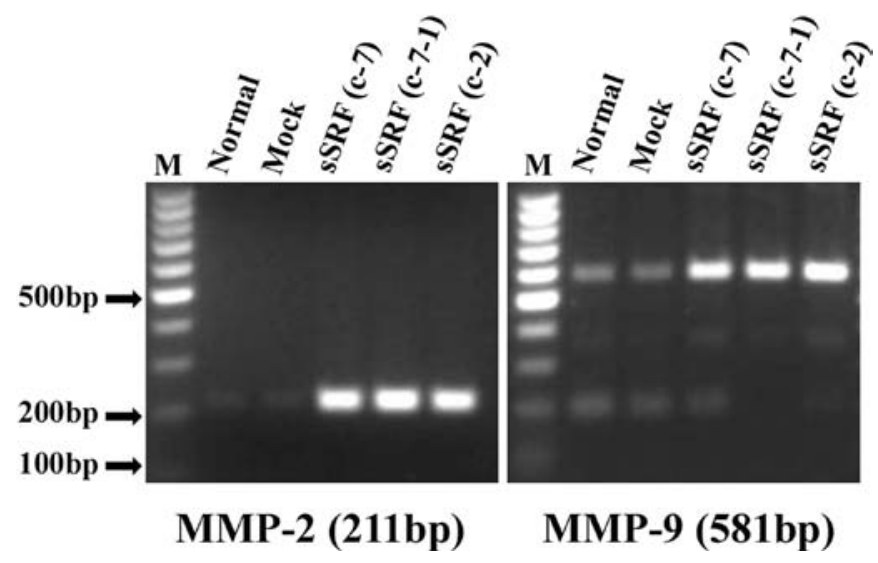

Figure 2. Enhanced expression of MMP-2 and -9 mRNA in HLE cells transfected with the SRF gene (three selected clones; C-2, C-7 and C-7-1).

HLE cells, SRF, the active form of MMP-2 and -9 was increased by 3.8-, 2.3-, and 2.2-fold, respectively (Fig. 3), when compared with those of control cells.

Enzyme activity of MMP-2 and -9 in HLE cells transfected with the SRF gene. Overexpression of SRF led to a significant increase in MMP-2, -9 enzyme activities at 0.1, 1, 5, and 10\% serum after serum starvation, compared with normal controls, respectively (Fig. 4). This result indicated that transfection of SRF cDNA in HCC cell induces activation of MMP-2 and -9. Taken together, these results indicated that SRF could induce an increase in expression of MMP-2 and -9 and also induce activation of these enzymes in HCC cells.

Overexpression of SRF stimulated cell migration. Incubation of SRF overexpressing HLE cells with 1, 5, and 10\% serum resulted in significant dose-dependent increases in cell migration, respectively (Fig. 5A). Overexpression of SRF in HLE cells led to significantly increased cell migration by 1.5- and 3.1-fold, when compared with those of the control at 12 and 24 h, respectively (Fig. 5B).

\section{Discussion}

Incidence of hepatocellular carcinoma (HCC) is increasing in many countries and is becoming one of the most common lethal tumors worldwide $(1,2)$. Although significant progress has been made in early detection, the overall outcome for patients with advanced or metastatic $\mathrm{HCC}$ remains poor (3). The morbidity and mortality experienced by HCC patients is due mainly to invasion and metastasis of the primary tumor. MMPs are up-regulated in almost every type of human cancer, including HCC, and their expression is associated with cancer cell invasion and metastasis (16-19). Recent studies have implicated expression of SRF in carcinogenesis and cancer progression in several cancers $(12,13,20-24)$. However, the relationship between expression of SRF and MMPs has not been examined, forming the basis for this study.

This study demonstrated the following for the first time: a) expression of SRF, MMP-2, and -9 protein was significantly elevated in HCC tissues when compared with corresponding non-tumor tissues, b) expression of SRF showed correlation with 

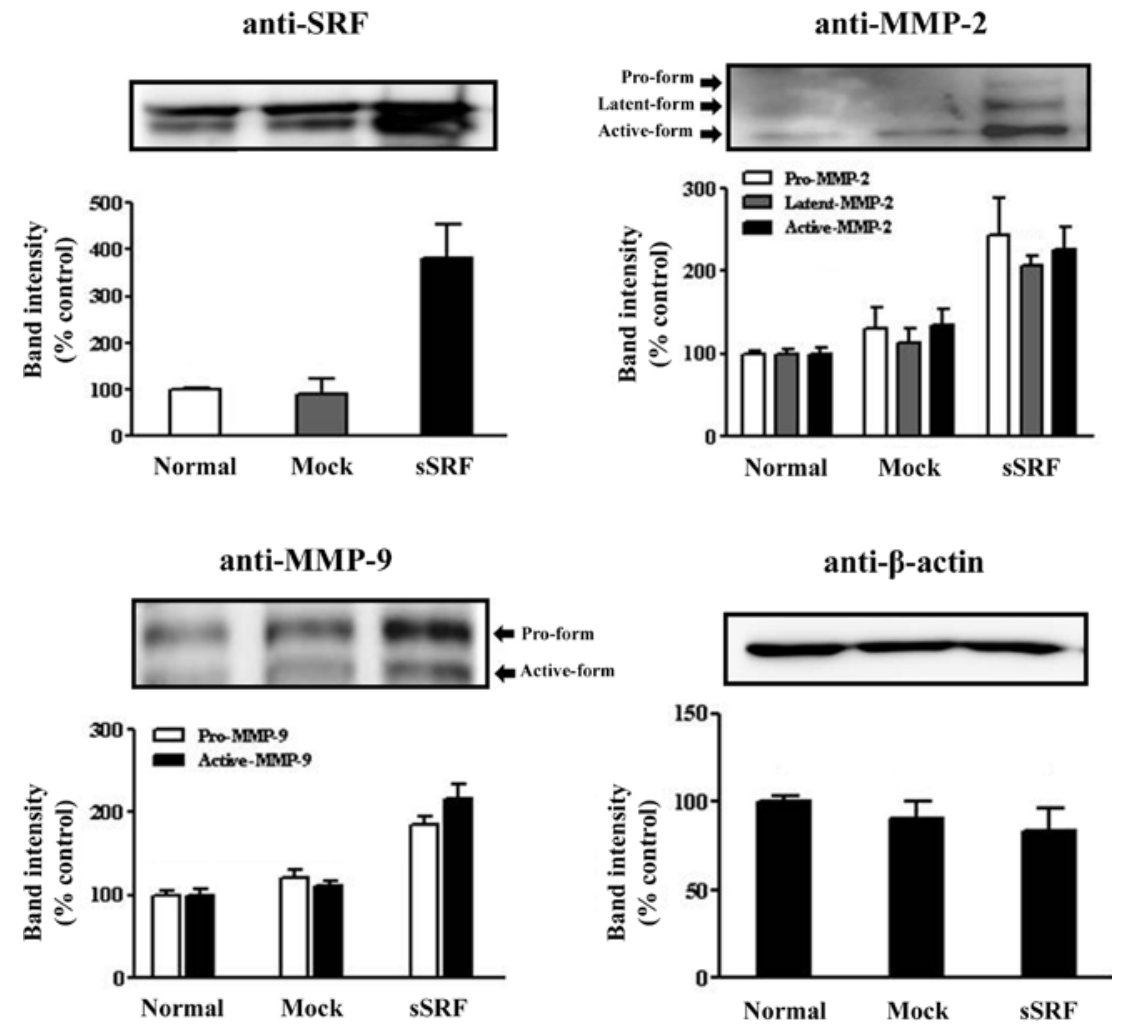

Figure 3. Enhanced expression of SRF, MMP-2, and -9 in SRF-transfected HLE cells. In SRF-transfected HLE cells, SRF, active form of MMP-2 and -9 were increased by 3.8-, 2.3-, and 2.2-fold, respectively.

MMP-2 and -9 expression in HCC tissues, c) overexpression of SRF led to increased expression levels of mRNA and protein of MMP-2 and -9 in HLE cells, d) overexpression of SRF also induced an increase in MMP-2, -9 enzyme activities and expression levels of the active form of MMP-2 and -9. In addition, overexpression of SRF resulted in enhanced HLE cell motility. These findings clearly indicate the important role of SRF in HCC cell migration through up-regulation of MMP-2 and -9 in $\mathrm{HCC}$.

Accumulating evidence has suggested that SRF plays multiple roles in carcinogenesis and metastasis in various cancers $(12,13,20-24)$. In this study, we found that expression of SRF is up-regulated in HCC tissues when compared with that of non-tumor tissues. We also found that overexpression of SRF resulted in enhanced HLE cell motility. We have previously demonstrated that expression of SRF in metastatic colorectal carcinoma cells is significantly higher than that of primary tumors (20). We have shown that expression of SRF correlates with tumor cell de-differentiation (23) in HCC and forced overexpression of SRF in HCC cells results in significantly increased cell growth and proliferation (13). Farra et al recently determined that SRF depletion by a siRNA affects expansion of highly and poorly differentiated HCC cell lines (22). Expression of SRF was associated with cell proliferation and poor patient survival in cholangiocarcinoma (24). Overexpression of SRF led to significantly enhanced cell migration and invasiveness of HCC cells through altered expression of mesenchymal markers and proteins involved in the Wnt/ $\beta$-catenin pathway. In addition, inhibition of SRF expression in poorly differentiated HCC cells by SRF antisense cDNA resulted in significantly decreased migration and invasion (13). Taken together, our data suggest that SRF expression may act as a tumor promoter and appears to be necessary for tumor progression in various cancers, including HCC.

MMPs are a major group of proteolytic enzymes that regulate cell-matrix composition (14-17). Considerable evidence exists on the role of MMPs in normal and pathologic conditions, including embryogenesis, inflammation, and disorders of the immune system, cardiovascular disease, and cancer. MMP-2 and MMP-9 degrade the extracellular matrix components of the basement membrane, removing tissue boundaries and facilitating cancer cell motility (14-17). MMP-2 and -9 have been implicated in migration and invasion of HCC cancer cells $(18,19)$. In this study, we found that overexpression of SRF increased production of mRNA of MMP-2 and -9 in HLE cells. Furthermore, overexpression of SRF also resulted in increased MMP-2, -9 enzyme activities and in the expression levels of the active form of MMP-2 and -9. This is in agreement with a previous study demonstrating that increased expression of SRF in pulmonary lymphangioleiomyomatosis (LAM) and overexpression of SRF up-regulates expression of MMP-2 and -14 in mouse lung fibroblasts (25). Zhe et al have shown that overexpression of SRF in human lung fibroblasts up-regulates urokinase-type plasminogen activator and finally increases MMP activities (26). They have concluded that SRF plays an important role in regulation of the plasminogen/MMP system, which allows degradation of extracellular matrix by LAM cells, consequently promoting destruction of lung parenchyma and expansion of lesions (26).

The mechanism whereby SRF up-regulates MMP-2 and -9 is currently unknown. SRF is a transcription factor, which binds 


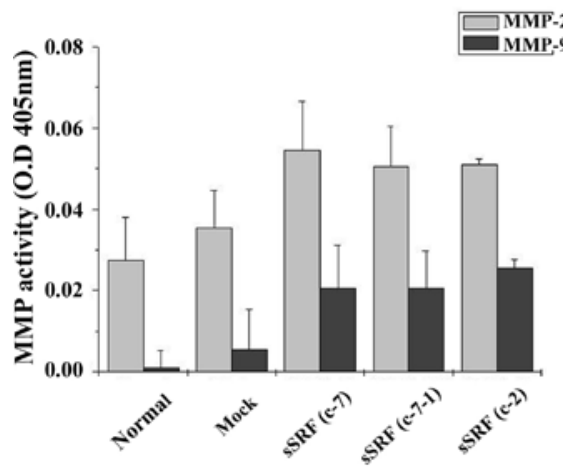

$0.1 \%$ FBS

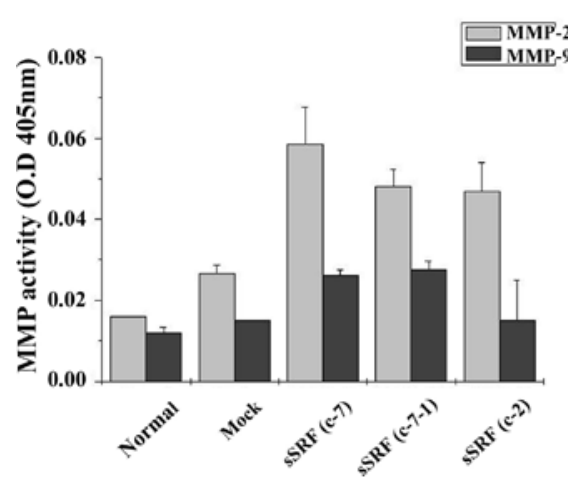

$5 \%$ FBS

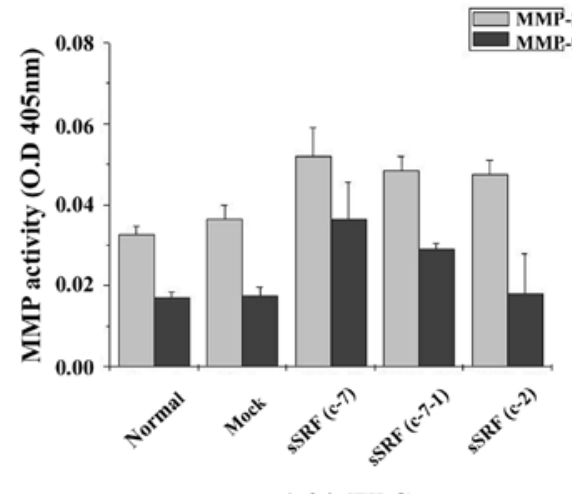

$1 \%$ FBS

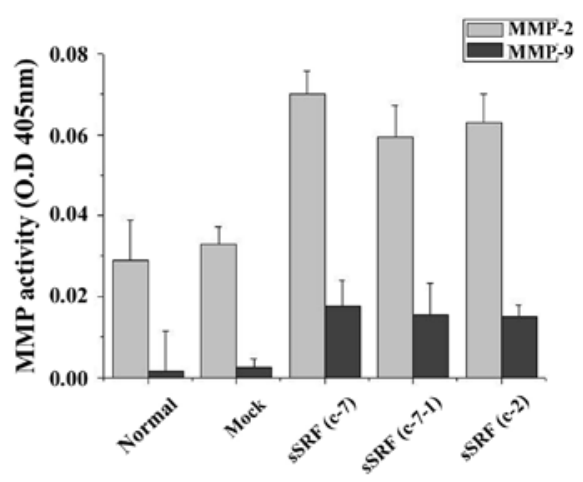

$10 \%$ FBS

Figure 4. Enzyme activity of MMP-2 and -9 in SRF-transfected HLE cells. Overexpression of SRF in HLE cells led to increased levels of enzyme activity of MMP-2 and -9 at $0.1,1,5$, and $10 \%$ serum when compared with those of normal controls, respectively.

A

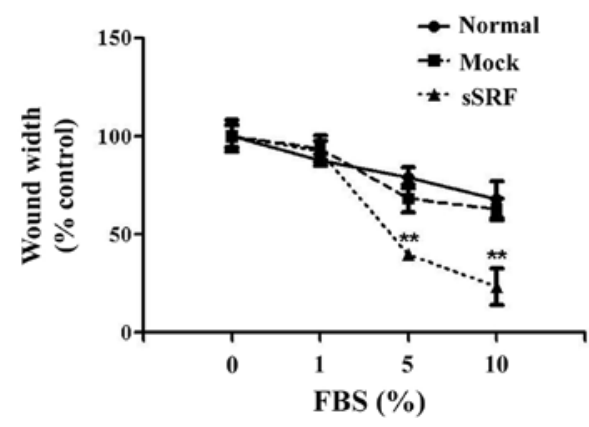

B

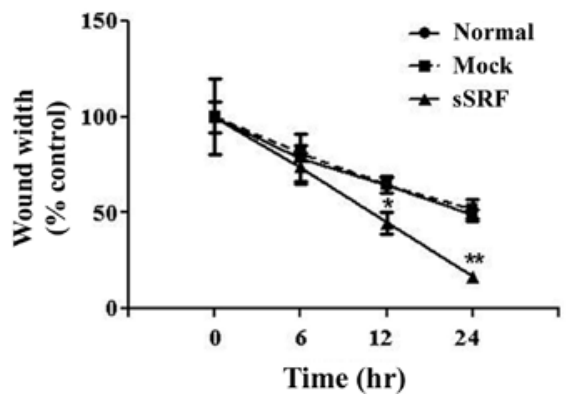

Figure 5. (A) Overexpression of SRF in HLE cells effectively increased cell migration by 2- and 3-fold when compared with those of the control at a concentration range of 5 and $10 \%$ serum for $24 \mathrm{~h}$, respectively ( $\left.{ }^{* *} \mathrm{P}<0.01\right)$. (B) Overexpression of SRF in HLE cells resulted in significantly increased cell migration by 1.5 - and 3.1-fold when compared with those of the control at 12 and $24 \mathrm{~h}$, respectively $\left({ }^{*} \mathrm{P}<0.05 ;{ }^{* *} \mathrm{P}<0.01\right)$. The experiment was independently repeated three times.

to an SRE associated with immediate early genes, such as $c$-Fos, FosB, Jun, and Egr-1 and -2, and controls cellular activities by regulation of these immediate early genes (8-10). Most MMPs respond to stimuli at the transcription level and are downstream targets of immediate-early genes, such as c-Fos and Jun, which are induced within minutes of cell stimulation and in the absence of new protein synthesis $(16,27)$. In papillary carcinoma of the thyroid, expression of SRF was up-regulated and it enhanced expression of the SRF target gene, $c$-Fos, which was associated with tumor progression and metastasis (21). Activator protein-1
(AP-1) complexes are heterodimers of proteins of two protooncogene (Fos and Jun gene) is found at $\sim 70 \mathrm{bp}$ in the promoter region of inducible MMP gene and is implicated in induction of MMPs $(16,28)$. Therefore, it is possible that SRF could control MMP expression by regulating expression of immediate early genes, including Fos and Jun genes. Although it is not clear whether overexpression of SRF itself or regulation of one or more of its target genes is responsible for activation of MMPs, the above findings indicate a critical role of SRF in modulation of the MMPs pathway in HCC. 
In conclusion, our study indicates that expression of SRF is closely related to regulation of the MMP system and that it may be one of the mechanisms for promotion of migration and invasion in human HCC cells.

\section{Acknowledgements}

This study was supported by the National Research Foundation of Korea Grant funded by the Korean Government (No. 20100029464) and by the Fund of Chonbuk National University Hospital Research Institute of Clinical Medicine. Tissue samples were provided by the Chonbuk National University Hospital, a member of the National Biobank of Korea, which is supported by the Ministry of Health, Welfare and Family Affairs.

\section{References}

1. Parkin DM, Bray F, Ferlay J and Pisani P: Global cancer statistics, 2002. CA Cancer J Clin 55: 74-108, 2005.

2. Ferlay J, Shin HR, Bray F, Forman D, Mathers C and Parkin DM: Estimates of worldwide burden of cancer in 2008: GLOBOCAN 2008. Int J Cancer 127: 2893-2917, 2010.

3. Befeler AS and Di Bisceglie AM: Hepatocellular carcinoma: diagnosis and treatment. Gastroenterology 122: 1609-1619, 2002.

4. Treisman R: Identification of a protein-binding site that mediates transcriptional response of the c-fos gene to serum factors. Cell 46: 567-574, 1986.

5. Treisman R: Identification and purification of a polypeptide that binds to the c-fos serum response element. EMBO J 6: 2711-2717, 1987.

6. Shore P and Sharrocks AD: The MADS-box family of transcription factors. Eur J Biochem 229: 1-3, 1995.

7. Norman C, Runswick M, Pollock R and Treisman R: Isolation and properties of cDNA clones encoding SRF, a transcription factor that binds to the c-fos serum response element. Cell 55: 989-1003, 1988.

8. Modak C and Chai J: Serum response factor: look into the gut. World J Gastroenterol 16: 2195-2201, 2010.

9. Chai $\mathbf{J}$ and Tarnawski AS: Serum response factor: discovery, biochemistry, biological roles and implications for tissue injury healing. J Physiol Pharmacol 53: 147-157, 2002.

10. Schratt G, Weinhold B, Lundberg AS, Schuck S, Berger J, Schwarz H, Weinberg RA, Ruther U and Nordheim A: Serum response factor is required for immediate-early gene activation yet is dispensable for proliferation of embryonic stem cells. Mol Cell Biol 21: 2933-2943, 2001

11. Chai J, Baatar D and Tarnawski A: Serum response factor promotes re-epithelialization and muscular structure restoration during gastric ulcer healing. Gastroenterology 126: 1809-1818, 2004.

12. Psichari E, Balmain A, Plows D, Zoumpourlis V and Pintzas A: High activity of serum response factor in the mesenchymal transition of epithelial tumor cells is regulated by RhoA signaling. J Biol Chem 277: 29490-29495, 2002.
13. Kwon CY, Kim KR, Choi HN, Chung MJ, Noh SJ, Kim DG, Kang MJ, Lee DG and Moon WS: The role of serum response factor in hepatocellular carcinoma: Implications for disease progression. Int J Oncol 37: 837-844, 2010.

14. Page-McCaw A, Ewald AJ and Werb Z: Matrix metalloproteinases and the regulation of tissue remodelling. Nat Rev Mol Cell Biol 8: 221-233, 2007.

15. Parks WC, Wilson CL and Lopez-Boado YS: Matrix metalloproteinases as modulators of inflammation and innate immunity. Nat Rev Immunol 4: 617-629, 2004.

16. Egeblad $\mathrm{M}$ and Werb Z: New functions for the matrix metalloproteinases in cancer progression. Nat Rev Cancer 2: 161-174, 2002.

17. Kessenbrock K, Plaks V and Werb Z: Matrix metalloproteinases: regulators of the tumor microenvironment. Cell 141: 52-67, 2010.

18. Giannelli G, Bergamini C, Marinosci F, Fransvea E, Quaranta M, Lupo L, Schiraldi O and Antonaci S: Clinical role of MMP-2/ TIMP-2 imbalance in hepatocellular carcinoma. Int J Cancer 97: 425-431, 2002.

19. Sakamoto Y, Mafune K, Mori M, Shiraishi T, Imamura H, Mori M, Takayama T and Makuuchi M: Overexpression of MMP-9 correlates with growth of small hepatocellular carcinoma. Int J Oncol 17: 237-243, 2000.

20. Choi HN, Kim KR, Lee JH, Park HS, Jang KY, Chung MJ, Hwang SE, Yu HC and Moon WS: Serum response factor enhances liver metastasis of colorectal carcinoma via alteration of the E-cadherin/ $\beta$-catenin complex. Oncol Rep 21: 57-63, 2009.

21. Kim HJ, Kim KR, Park HS, Jang KY, Chung MJ, Shong M and Moon WS: The expression and role of serum response factor in papillary carcinoma of the thyroid. Int J Oncol 35: 49-55, 2009.

22. Farra R, Dapas B, Pozzato G, Giansante C, Heidenreich O, Uxa L, Zennaro C, Guarnieri G and Grassi G: Serum response factor depletion affects the proliferation of the hepatocellular carcinoma cells. HepG2 and JHH6. Biochimie 92: 455-463, 2010.

23. Park MY, Kim KR, Park HS, Park BH, Choi HN, Jang KY, Chung MJ, Kang MJ, Lee DG and Moon WS: Expression of the serum response factor in hepatocellular carcinoma: Implications for epithelial-mesenchymal transition. Int J Oncol 31: 1309-1315, 2007.

24. Park SY, Jang KY, Kim YN, Kim HJ, Park HS, Chung MJ, Yu HC, Cho BH, Kim KR and Moon WS: Expression and prognostic significance of serum response factor in cholangiocarcinoma. Korean J Pathol 43: 517-522, 2009.

25. Zhe X, Yang Y, Jakkaraju S and Schuger L: Tissue inhibitor of metalloproteinase-3 downregulation in lymphangioleiomyomatosis: potential consequence of abnormal serum response factor expression. Am J Respir Cell Mol Biol 28: 504-511, 2003.

26. Zhe X, Yang Y and Schuger L: Imbalanced plasminogen system in lymphangioleiomyomatosis: potential role of serum response factor. Am J Respir Cell Mol Biol 32: 28-34, 2005.

27. Sampieri CL, Nuttall RK, Young DA, Goldspink D, Clark IM and Edward DR: Activatin of p38 and JNK MAP kinase pathways abrogates requirement for new protein synthesis for phorbol ester mediated induction of select MMP and TIMP genes. Matrix Biol 27: 128-138, 2008

28. Yan C and Boyd DD: Regulation of matrix metalloproteinase gene expression. J Cell Physiol 211: 19-26, 2007. 